\title{
Peningkatan Komitmen Organisasi melalui Penguatan Efikasi Diri dan Kualitas Kehidupan Kerja
}

Submitted Date :

19 May 2021

Accepted Date :

30 September 2021

\author{
Derita Qurbani* \\ Universitas Pamulang, Tangerang Selatan \\ derita01582@unpam.ac.id \\ Dede Solihin \\ Universitas Pamulang, Tangerang Selatan \\ desolihin86@gmail.com
}

\section{Suggested Citation:}

Zeb, S., \& Nawaz, A. (2016). Impacts of Self-Efficacy on Organizational Commitment of Academicians A Case of Gomal University, Dera Ismail Khan, Khyber Pakhtunkhwa, Pakistan. Information and Knowledge Management, 6(1), $36-42$.

Abstract:

Competition for universities in Indonesia, especially private universities, is always getting tougher every year. The number of existing private universities increasingly provides competitive value with the aim of working on prospective students so that the chosen institution or college remains superior and attractive and remains in demand. The purpose of this study was to examine the effect of self-efficacy and quality of work life on organizational commitment. This type of research is quantitative research using the causality method. The sample in this study was 135 respondents obtained from purposive sampling technique. Data was collected using a questionnaire, while data analysis was carried out using Partial Least Squares (PLS). The results showed that self-efficacy and the quality of work life had an effect on organizational commitment.

Keywords: Organizational Commitment; Quality of Work Life; Self-Efficacy

Abstrak:

Persaingan perguruan tinggi di Indonesia, terutama perguruan tinggi swasta setiap tahun selalu semakin ketat. Banyaknya perguruan tinggi swasta yang ada semakin memberikan nilai persaingan dengan tujuan menggarap calon mahasiswa agar institusi atau perguruan tinggi yang dipilih menjadi tetap unggul dan menarik serta tetap diminati. Tujuan penelitian ini adalah untuk menguji pengaruh efikasi diri dan kualitas kehidupan kerja terhadap komitmen organisasi. Jenis penelitian adalah penelitian kuantitatif dengan menggunakan metode kasualitas. Sampel dalam penelitian ini sebanyak 135 responden yang diperoleh dari teknik purposive sampling. Pengumpulan data dengan menggunakan kuesioner, sementara analisis data dilakukan menggunakan Partial Least Squares (PLS). Hasil penelitian menunjukkan bahwa efikasi diri dan kualitas kehidupan kerja berpengaruh terhadap komitmen organisasi.

Kata Kunci: Efikasi Diri; Komitmen Organisasi; Kualitas Kehidupan Kerja

JEL Classification: M54

*Corresponding Author 


\section{Latar Belakang}

Keberadaan Perguruan Tinggi memiliki peran penting dalam meningkatkan daya saing bangsa, di dalam perkembangannya perlu dipahami juga jika keberadaan Perguruan Tinggi dihadapkan pada kondisi persaingan sebagaimana entitas bisnis pada umumnya. Beberapa persaingan yang dihadapi oleh perguruan tinggi yaitu pertumbuhan perguruan tinggi, menarik minat calon mahasiswa dan Doktor atau Profesor sebagai pendidik serta penggalangan dana. Kondisi tersebut memaksa salah satu mekanisme perguruan tinggi dalam menghadapi persaingan tersebut adalah dengan menampilkan keunggulan maupun sumberdaya yang dimiliki, (Totoh, 2020). Persaingan yang terjadi antar lembaga pendidikan tinggi saat ini tidak saja terjadi antara Perguruan Tinggi Swasta (PTS) dengan Perguruan Tinggi Negeri (PTN), tetapi persaingan yang lebih hebat terjadi pula antar PTS. Bagi penyedia jasa pendidikan tinggi swasta, pelanggan yang langsung menikmati jasa yang ditawarkan adalah mahasiswa, pesaing adalah penyedia jasa pendidikan yang sejenis pada jenjang yang sama, (Risdwiyanto dan Kurniyati, 2015).

Tuntutan dalam dunia pendidikan menimbulkan persaingan yang sangat ketat, sehingga setiap Perguruan Tinggi berupaya untuk mengerahkan seluruh kemampuannya guna menarik calon mahasiswa baru. Dosen merupakan agent of change dan dapat merubah pola pikir mahasiswa, karena keberhasilan mahasiswa akan lebih bergantung pada kemampuan dosen dalam melaksanakan pekerjaan dan tugasnya secara efektif, (Manurung, 2016). Betapa pentingnya faktor komitmen kerja bagi dosen, dikarenakan komitmen kerja itu akan mendorong seseorang untuk termotivasi dalam bekerja dengan baik, oleh karena itu komitmen seorang dosen dapat memberikan kontribusi terhadap peningkatan kinerja perguruan tinggi, (Sumual, 2014). Dosen yang berkomitmen pada organisasi akan lebih mampu bertahan sebagai bagian dari organisasi dibandingkan dosen yang tidak berkomitmen pada organisasi, (Muraga, et al., 2019).

Penelitian ini dilakukan pada Universitas Pamulang dimana berdasarkan hasil pengamatan penulis mengindikasikan rendahnya komitmen dosen untuk meningkatkan jenjang kepangkatan yang dimilikinya, padahal kepangkatan dosen merupakan syarat utama karir seorang dosen untuk mencapai level tertinggi.

Tabel 1. Data Kepangkatan Dosen-Dosen UNPAM

\begin{tabular}{clcc} 
No & Kepangkatan & Jumlah & Presentase \\
\hline 1 & Tanpa Kepangkatan & 860 & $49,11 \%$ \\
2 & Asisten Ahli & 789 & $45,06 \%$ \\
3 & Lektor & 94 & $5,37 \%$ \\
4 & Lektor Kepala & 8 & $0,46 \%$ \\
5 & Guru Besar & - & $0,00 \%$ \\
& Total & 1.751 & $100 \%$ \\
\hline
\end{tabular}

Sumber : Kepegawaian UNPAM (2021)

Pada tabel tersebut terkait kepangkatan dosen universitas Pamulang, di mana dosen tanpa kepangkatan sebanyak 860 dosen (49,11\%), Asisten Ahli sebanyak 789 dosen (45,05\%), Lektor 94 dosen (5,37\%), dan Lektor Kepala 8 dosen $(0,46 \%)$. Data ini menjelaskan mayoritas dosen di Universitas Pamulanag adalah Tanpa Kepangkatan sedangkan dosen yang berpangkat Asisten Ahli, Lektor, Lektor Kepala dan Guru Besar sangat minim, hal tersebut mengindikasikan rendahnya komitmen dosen untuk meningkatkan karir kepangkatan mereka. Penelitian tentang komitmen organisasi saat ini sebagian besar didorong oleh organisasi industri dan psikologi pekerjaan. Komitmen dosen saat ini kurang diperhatikan, dan komitmen dosen sangat penting karena meningkatkan tingkat retensi dosen, kinerja, minat kerja dan peningkatan kesadaran kewargaan organisasi. Demikian pula, dosen dengan tingkat komitmen yang lebih tinggi lebih banyak terlibat dalam pengajaran di kelas daripada dosen dengan tingkat komitmen yang lebih rendah, (Zeb \& Nawaz, 2016).

Akhtar et al., (2013) menyatakan bahwa efikasi diri berhubungan positif dengan komitmen keorganisasian. Karyawan yang memiliki tingkat efikasi diri yang tinggi akan memiliki tingkat komitmen yang tinggi pula. Agarwal \& Mishra (2016) juga menemukan bahwa efikasi diri berpengaruh signifikan terhadap komitmen keorganisasian. Hal senada pada penelitian Garcia (2015) yang menyatakan bahwa efikasi diri memiliki pengaruh positif dan signifikan terhadap komitmen keorganisasian. Efikasi diri ialah perilaku kepercayaan seorang terhadap keahlian dirinya dalam melakukan tugas menggapai sesuatu keberhasilan ataupun tujuan yang sudah diresmikan sebelumnya, (Manurung, 2016). Pribadi dengan efikasi diri yang tinggi akan sanggup mempengaruhi komitmen profesional yang tinggi, sebaliknya pribadi dengan tingkatan diri yang rendah akan mempunyai tingkatan komitmen yang rendah pada profesi pula, (Sumual, 2014). Dengan kata lain, 
efikasi diri ialah kepercayaan pegawai terhadap keahlian dalam menuntaskan tugasnya, yang berarti dia secara langsung sudah berkomitmen terhadap organisasi.

Valentine (2014) mengungkapkan bahwa kualitas kehidupan kerja menjadi salah satu faktor yang dapat mempengaruhi komitmen organisasi. Hasil penelitian yang telah dilakukan oleh Sajjad dan Abbasi (2015) menunjukkan bahwa terdapat hubungan antara kualitas kehidupan kerja terhadap komitmen organisasi. Kaswan (2017) berpendapat bahwa kualitas kehidupan kerja yang baik akan berdampak positif pada sikap kerja karyawan di perusahaan. Sikap kerja positif tersebut diantaranya yakni tingkat kepuasan kerja, komitmen organisasi, keterlibatan kerja, semangat kerja dan perilaku kewargaan organisasi yang tinggi, selain itu karyawan akan memiliki persepsi yang baik mengenai keadilan dan dukungan organisasi. Dengan demikian diharapkan pihak universitas dapat menciptakan kehidupan kerja yang kondusif baik fisik maupun non fisik. Kondisi seperti ini dapat memberikan kesempatan kepada dosen untuk mengembangkan diri, memperoleh kesejahteraan untuk memenuhi kebutuhan hidup, serta memiliki lingkungan kerja yang aman dan menyenangkan, yang pada akhirnya akan membantu meningkatkan prestasi akademik universitas, (Adikoeswanto, et al. 2020).

Penelitian ini didasari adanya research gap pada penelitian terdahulu, dimana terdapat perbedaan hasil penelitian antara pengaruh efikasi diri terhadap komitmen organisasi. Pada penelitian Zeb \& Nawaz (2016); Agarwal \& Mishra (2016); serta Verianto (2019) menunjukkan hasil bahwa efikasi diri berpengaruh signifikan terhadap komitmen organisasi namun penelitian tersebut tidak sejalan dan bertentangan dengan penelitian yang dilakukan oleh Fitriani dan Purwanto (2019) serta Yokoyama (2019) dimana hasil penelitian menunjukkan bahwa variabel efikasi diri tidak berpengaruh signifikan terhadap komitmen organisasi.

Perbedaan hasil penelitian juga ditemukan pada penelitian mengenai pengaruh kualitas kehidupan kerja terhadap komitmen organisasi. Pada penelitian Maharani (2018); Muraga et al., (2014); Helastika (2019); serta Indaswasri (2014) menunjukkan hasil bahwa kualitas kehidupan kerja berpengaruh signifikan terhadap komitmen organisasi. Namun hasil penelitian tersebut tidak sejalan dengan penelitian Asharini, Hardyastuti, dan Irham (2018), dimana temuan penelitian menunjukkan bahwa kualitas kehidupan kerja tidak berpengaruh terhadap komitmen organisasi.

Verianto (2019), mendefinisikan efikasi diri sebagai keyakinan seseorang untuk melaksanakan pekerjaan dalam situasi sulit. Efikasi diri merupakan salah satu aspek pengetahuan diri yang paling berpengaruh dalam kehidupan manusia sehari-hari. Hal ini dikarenakan efikasi diri yang dimiliki mempengaruhi individu dalam menentukan tindakan yang akan dilakukan untuk mencapai suatu tujuan termasuk memperkirakan berbagai kejadian yang akan dihadapi, (Maria, et al., 2021). Sedangkan menurut Qomariah (2014) efikasi diri merupakan kemampuan yang dimiliki untuk melakukan sesuatu dalam situasi yang khusus.

Hashempour et al., (2018) menyatakan bahwa kualitas kehidupan kerja adalah seperangkat kondisi kerja nyata dalam suatu organisasi, seperti gaji yang adil dan memadai, lingkungan kerja yang aman dan higienis, kesempatan yang sama untuk pertumbuhan dan keamanan yang berkelanjutan, legalitas organisasi, afiliasi sosial dalam kehidupan kerja, kehidupan secara keseluruhan, ruang, kesatuan sosial, dan pengembangan kemampuan manusia. Menurut Chrisienty (2015), sejatinya kualitas kehidupan kerja ialah teknik dalam mengembangkan sebuah perusahaan yang dirancang dalam peningkatan akan fungsi dari perusahaan yang memanusiakan pekerja dan lingkungan kerjanya, sehingga nantinya akan demokratis serta melibatkan langsung para karyawannya dalam keputusan yang diambil oleh perusahaan tersebut. Adapun menurut Endayani dan Saman (2020) kualitas kehidupan kerja merupakan suatu kondisi atau keadaan sebagai hasil dari interaksi antara individu dan pekerjaannya yang dapat membuat karyawan lebih produktif dan menimbulkan kepuasan kerja.

Menurut Jehanzeb \& Mohanty (2018) Komitmen organisasi diartikan sebagai kondisi psikologis yang menandai keterikatan antara karyawan dengan organisasi dan berdampak pada keputusan untuk melanjutkan atau memberhentikan keanggotaan organisasi. Komitmen organisasi ditentukan dengan menerima nilai dan tujuan organisasi, mewakili kemauan, dan keinginan organisasi untuk bekerja keras serta mempertahankan keanggotaan organisasi, (Adikoeswanto, et al., 2020). Menurut Widodo et al., (2019) komitmen organisasi adalah derajat karyawan percaya dan menerima tujuan-tujuan organisasi dan akan tetap tinggal atau tidak akan meninggalkan organisasi.

Giri et al., (2016), menyatakkan bahwa dimensi komitmen organisasional meliputi affective atau moral commitment, continuance atau calculative commitment, dan normative commitment. Affective atau moral commitment terjadi ketika individu sepenuhnya terikat pada tujuan dan nilai-nilai organisasi. Continuance atau 
calculative commitment terjadi ketika individu mendasarkan hubungannya dengan organisasi pada apa yang mereka terima sebagai imbalan usahanya dan apa yang akan hilang ketika mereka berhenti (seperti gaji, benefit, pergaulan). Normative Commitment terjadi ketika individu tetap di organisasi berdasarkan standar perilaku dan norma sosial yang diharapkan.

Efikasi diri berkaitan erat dengan komitmen organisasi dimana bila pegawai mempunyai efikasi diri yang tinggi maka komitmen terhadap apa yang dikerjakannya juga akan semakin tinggi, (Sumual, 2014). Individuindividu dengan efikasi diri tinggi memiliki komitmen dalam memecahkan masalahnya dan tidak akan menyerah ketika menemukan bahwa strategi yang sedang digunakan itu tidak berhasil, (Verianto, 2019). Hasil penelitian Sinaga (2018) membuktikan bahwa penguatan Efikasi diri berpengaruh secara signifikan terhadap peningkatan komitmen organisasi. Hasil riset empiris Zeb \& Nawaz (2016), memperlihatkan efikasi diri mempengaruhi secara positif terhadap komitmen organisasional dosen di tingkatan universitas. Penelitian Agarwal \& Mishra (2016) menunjukkan hasil bahwa efikasi diri berpengaruh terhadap komitmen organisasional. Selanjutnya penelitian Verianto (2019) menunjukkan hasil efikasi diri yang baik dapat mempengaruhi komitmen organisasi karyawan.

Pengaruh kualitas kehidupan kerja dengan komitmen organisasi adalah ketika kualitas kehidupan kerja seorang karyawan baik maka komitmen organisasinya akan tinggi. Sebaliknya jika kualitas kehidupan kerjanya rendah maka komitmen organisasinya pun akan rendah pula sehingga menyebabkan turnover pada organisasi, (Kaunang, et al., 2017). Kualitas kehidupan kerja yang baik akan membuat orang merasa puas dengan pekerjaannya sendiri, serta memungkinkan seorang karyawan untuk menikmati pekerjaan yang ditugaskan dan menilai bahwa karyawan dengan kualitas kerja yang baik akan bersedia untuk terus terlibat dalam pekerjaannya sendiri karena keakraban pekerjaannya, (Larasati dan Hasanati, 2018). Dari hasil penelitian Muraga et al., (2014) membuktikan bahwa kualitas kehidupan kerja berpengaruh signifikan terhadap komitmen organisasi karyawan. Penelitian yang sama dilakukan oleh Helastika (2019) menunjukkan terdapat hubungan yang sangat erat antara variabel kualitas kehidupan kerja dengan komitmen organisasi. Penelitian Indaswasri (2014) menunjukkan hasil kualitas kehidupan kerja berpengaruh positif terhadap komitmen organisasional.

Berdasarkan latar belakang yang telah diuraikan, maka tujuan penelitian ini adalah untuk menguji pengaruh efikasi diri dan kualitas kehidupan kerja terhadap komitmen organisasi. Secara empiris, beberapa penelitian yang telah dilakukan sebelumnya masih belum dapat disimpulkan karena hasil yang tidak konsisten dalam menjelaskan peran masing-masing variabel terhadap komitmen organisasi, oleh karena itu masih ada kesenjangan atau gap secara empiris sehingga masih perlu adanya penelitian lanjutan yang menguji kembali tentang peningkatan komitmen organisasi.

\section{Metode Penelitian}

Jenis penelitian yang digunakan adalah penelitian kuantitatif dengan menggunakan data primer berupa survei. Penelitian ini menggunakan desain studi kausal, menurut Sugiyono (2017) penelitian kausal adalah hubungan yang bersifat sebab akibat. Studi kausalitas digunakan karena penelitian ini bertujuan untuk mengetahui hubungan sebab akibat yang terjadi antara variabel independen dengan variabel dependen. Penelitian ini dilaksanakan pada bulan Februari 2021 - April 2021. Metode pengumpulan data menggunakan kuesioner yang dibuat dengan google form. Populasi dalam penelitian ini adalah seluruh dosen dari Universitas Pamulang. Metode pengambilan sampel yang digunakan adalah non-probability sampling dengan teknik purposive sampling. Dalam non-probability sampling, tidak semua elemen mempunyai peluang untuk terpilih menjadi sampel (Sugiyono, 2017). Sampel dalam penelitian ini berjumlah 135 responden. Hipotesis penelitian diuji menggunakan analisis Partial Least Square Structural Equation Modelling (PLS SEM).

\section{Hasil Penelitian}

Universitas Pamulang didirikan pada tahun 2000 oleh Yayasan Prima Jaya yang diketuai oleh Drs. Wayan. Namun karena ketidakmampuan Yayasan Prima Jaya dalam mengelola suatu Universitas, maka merekapun mengalihkan kepemilikan dan pengelolaannya kepada Yayasan Sasmita Jaya pada awal tahun 2005. Setelah berganti manajemen, maka berganti pulalah tujuan yang ingin dicapai Universitas Pamulang. Oleh karena itu Universitas Pamulang selalu mengangkat tenaga pengajar dan staff administrasi yang berkompeten dibidangnya. Kamipun juga melakukan pengembangan dibidang kurikulum yang disesuaikan dengan kebutuhan dunia kerja, sehingga seluruh lulusan Universitas Pamulang diterima dengan baik dalam dunia kerja. 
Tabel 2. Karakteristik Responden

\begin{tabular}{rlcc}
\hline \multicolumn{2}{c}{ Karakteristik Responden } & Total & Percentage (\%) \\
\hline Jenis Kelamin & & \\
1. & Perempuan & 60 & $44 \%$ \\
2. Laki-Laki & 75 & $56 \%$ \\
Usia & & 135 & $100 \%$ \\
1. 20-30 Tahun & & \\
2. & $31-40$ Tahun & 13 & $10 \%$ \\
3. 41-50 Tahun & 66 & $49 \%$ \\
4. & $>$ 51 Tahun & 34 & $25 \%$ \\
& & 22 & $16 \%$ \\
Lama Bekerja & 135 & $100 \%$ \\
1. 1-3 Tahun & & \\
2. 4-6 Tahun & 7 & $5 \%$ \\
3. & $7-9$ Tahun & 87 & $64 \%$ \\
4. & $>10$ Tahun & 18 & $13 \%$ \\
Pendidikan Terakhir & 23 & $17 \%$ \\
1. S2 & 135 & 100 \\
2. S3 & 117 & $87 \%$ \\
\hline
\end{tabular}

Sumber: Data diolah (2021)

Data di atas menunjukkan bahwa jumlah dosen laki-laki paling dominan yaitu sebanyak 75 orang (56\%) dibandingkan 60 orang (44\%) dosen perempuan. Dosen yang paling dominan berusia 31-40 tahun sebanyak 66 orang (49\%), sedangkan jumlah dosen minimal berusia 20-30 tahun sebanyak 13 orang (10\%). Masa kerja dosen paling dominan adalah 4-6 tahun sebanyak 87 orang (64\%), sedangkan minimal 1-3 tahun sebanyak 7 orang (5\%). Sedangkan dosen berpendidikan S2 paling dominan sebanyak 117 orang (87\%) dan berpendidikan minimal sebanyak 18 orang doktor (13\%).

\section{Outer Model Evaluation}

Validitas konvergen (Convergent Validity) bertujuan untuk mengetahui validitas setiap hubungan antara indikator dengan konstruk atau variabel latennya, (Ghozali dan Latan, 2016). Validitas konvergen dari model pengukuran dengan refleksif indikator dinilai berdasarkan korelasi antara skor item atau component score dengan skor variabel laten atau construct score yang diestimasi dengan program PLS dengan nilai loading faktor indikatorindikator yang tersaji pada tabel 3 .

Nilai convergent validity adalah nilai loading faktor pada variabel laten dengan indikator-indikatornya, nilai yang diharapkan melebihi dari angka $>0.70$ atau sering digunakan batas 0,60 sebagai batasan minimal dari nilai loading faktor (Ghozali dan Latan, 2016). Berdasarkan Tabel 3 terlihat bahwa uji validitas pada semua indikator penelitian ini telah memenuhi persyaratan penelitian, artinya semua indikator memiliki validitas yang baik. Selain itu nilai Average Variant Extracted (AVE) variabel efikasi diri, kualitas kehidupan kerja dan komitmen organisasi > 0,50 , dengan demikian dapat dikatakan bahwa setiap variabel memiliki validitas diskriminatif yang baik.

Pada Tabel 4 perbandingan nilai AVE menampilkan hasil tiap-tiap nilai tersebut lebih besar dari pada korelasi antar variabel lain, sehingga bisa disimpulkan jika seluruh variabel laten dalam riset ini mempunyai validitas struktural serta diskriminasi yang baik. 
Tabel 3. Convergent Validity dan AVE

\begin{tabular}{|c|c|c|c|c|}
\hline Variabel & Indikator & Outer Loading & AVE & Keputusan \\
\hline \multirow{6}{*}{$\begin{array}{l}\text { Efikasi Diri } \\
\quad\left(X_{1}\right)\end{array}$} & X1.1 & 0,900 & \multirow{6}{*}{0,878} & Valid \\
\hline & $\mathrm{X} 1.2$ & 0,972 & & Valid \\
\hline & $\mathrm{X} 1.3$ & 0,948 & & Valid \\
\hline & $\mathrm{X} 1.4$ & 0,964 & & Valid \\
\hline & $\mathrm{X} 1.5$ & 0,937 & & Valid \\
\hline & $\mathrm{X} 1.6$ & 0,898 & & Valid \\
\hline \multirow{9}{*}{$\begin{array}{c}\text { Kualitas } \\
\text { Kehidupan } \\
\text { kerja }\left(X_{2}\right)\end{array}$} & $X 2.1$ & 0,843 & \multirow{9}{*}{0,953} & Valid \\
\hline & $X 2.2$ & 0,876 & & Valid \\
\hline & $X 2.3$ & 0,891 & & Valid \\
\hline & X2.4 & 0,897 & & Valid \\
\hline & $X 2.5$ & 0,922 & & Valid \\
\hline & $\mathrm{X} 2.6$ & 0,730 & & Valid \\
\hline & $X 2.7$ & 0,922 & & Valid \\
\hline & $\mathrm{X} 2.8$ & 0,867 & & Valid \\
\hline & X2.9 & 0,878 & & Valid \\
\hline \multirow{10}{*}{$\begin{array}{c}\text { Komitmen } \\
\text { Organisasi } \\
\text { (Y) }\end{array}$} & Y1 & 0,978 & \multirow{10}{*}{0,759} & Valid \\
\hline & Y2 & 0,993 & & Valid \\
\hline & $Y 3$ & 0,951 & & Valid \\
\hline & Y4 & 0,979 & & Valid \\
\hline & Y5 & 0,969 & & Valid \\
\hline & Y6 & 0,980 & & Valid \\
\hline & Y7 & 0,976 & & Valid \\
\hline & Y8 & 0,986 & & Valid \\
\hline & Y9 & 0,992 & & Valid \\
\hline & Y10 & 0,955 & & Valid \\
\hline
\end{tabular}

Sumber : Data Diolah (2021)

Table 4. Discriminant Validity Test Result (Fornell Lacker Criterium)

\begin{tabular}{lrrr}
\multicolumn{1}{c}{ Variabel } & Efikasi Diri & Komitmen Organisasi & Kualitas Kehidupan Kerja \\
\hline Efikasi Diri & 0,937 & & \\
Komitmen Organisasi & 0,831 & 0,976 & \\
Kualitas Kehidupan Kerja & 0,790 & 0,730 & 0,871 \\
\hline
\end{tabular}

Sumber : Data Diolah (2021)

Tabel 5. Uji Cronbach's Alpha dan Composite Reliability

\begin{tabular}{lccc}
\multicolumn{1}{c}{ Variabel } & Cronbach's Alpha & Composite Reliability & Keputusan \\
\hline Efikasi Diri & 0,972 & 0,977 & Reliabel \\
Kualitas Kehidupan Kerja & 0,960 & 0,966 & Reliabel \\
Komitmen Organisasi & 0,994 & 0,995 & Reliabel \\
\hline
\end{tabular}

Sumber : Data Diolah (2021)

Dari hasil uji Cronbachs alpha dan reliabilitas komposit menunjukkan nilai yang menggembirakan karena semua variabel laten memiliki nilai cronbachs alpha dan reliabilitas diatas 0,70 yang berarti semua variabel laten dianggap reliabel. 
Tabel 6. Hasil Uji R-Square

\section{Sumber : Data Diolah (2021)}

\section{R Square Adjusted R Square}

Komitmen Organisasi $\quad 0,706 \quad 0,701$

Evaluasi koefisien determinasi $\left(R^{2}\right)$ komitmen organisasi sebesar $0,706\left(R^{2}=70,6 \%\right)$, yang berarti model yang baik. Artinya presentase besarnya komitmen organisasi dapat dijelaskan oleh efikasi diri dan kualitas kehidupan kerja sebesar 70,6\% sedangkan selebihnya 29,4\% dijelaskan oleh variabel lain diluar yang diteliti.

\section{Test Result of Goodness of Fit Model}

$$
\begin{aligned}
& \text { Q-Square }=1-\left[\left(1-R^{21}\right)\right. \\
& \text { Q-Square }=1-(1-0,701) \\
& \text { Q-Square }=1-0,299 \\
& \text { Q-Square }=0,701
\end{aligned}
$$

Diketahui bahwa melalui proses blindfolding variabel komitmen organisasi memiliki nilai Q-Square sebesar 0,701 dengan demikian Q-Square > 0. Artinya variabel dependen memiliki relevansi prediktif atau menjelaskan bahwa variabel independen memiliki relevansi prediktif terhadap variabel dependen yang terpengaruh.

\section{Inner Model Evaluation}

Jika nilai sampel asli menunjukkan nilai positif maka variabel memiliki hubungan positif (begitu pula sebaliknya). Jika berdasarkan nilai T-statistik syarat T-statistics > 1,96 (taraf signifikansi 5\%) dan nilai P-value harus lebih

\begin{tabular}{|c|c|c|c|c|c|}
\hline Hipotesis & Variabel & $\begin{array}{c}\text { Original } \\
\text { Sample (0) }\end{array}$ & $\begin{array}{c}\mathrm{T} \\
\text { Statistics }\end{array}$ & P Values & Ket \\
\hline $\mathrm{H} 1$ & Efikasi Diri -> Komitmen Organisasi & 0,678 & 11,182 & 0,000 & Significant \\
\hline $\mathrm{H} 2$ & $\begin{array}{l}\text { Kualitas Kehidupan Kerja -> Komitmen } \\
\text { Organisasi }\end{array}$ & 0,195 & 2,822 & 0,005 & Significant \\
\hline
\end{tabular}
kecil dari 0,05 sehingga dapat disimpulkan bahwa hubungan antar variabel yang diuji dinyatakan memiliki pengaruh yang signifikan (Ghozali dan Latan, 2016).

Tabel 7. Pengujian Hipotesis

Sumber : Data Diolah (2021)

Dari hasil pengujian tersebut dapat terlihat pengaruh efikasi diri terhadap komitmen organisasi memiliki nilai original sampel 0,678 (positif) dan $p$ value $0,000<0,05$ yang berarti efikasi diri memiliki pengaruh signifikan terhadap komitmen organisasi sehingga $\mathrm{H} 1$ diterima. Nilai original sampel 0,678 (positif) memiliki pengaruh yang searah yang berarti bila efikasi diri dinaikan sebesar 0,678 unit maka komitmen organisasi akan meningkat sebesar 0,678 unit dengan asumsi variabel kualitas kehidupan kerja dianggap konstan.

Kemudian pengaruh kualitas kehidupan kerja terhadap komitmen organisasi memiliki nilai original sampel 0,195 (positif) dan $p$ value $0,005<0,05$ yang berarti kualitas kehidupan kerja memiliki pengaruh signifikan terhadap komitmen organisasi sehingga $\mathrm{H} 2$ diterima. Nilai original sampel 0,195 (positif) memiliki pengaruh yang searah yang berarti bila kualitas kehidupan kerja dinaikan sebesar 0,195 unit maka komitmen organisasi akan meningkat sebesar 0,195 unit dengan asumsi variabel efikasi diri dianggap konstan.

\section{Pembahasan}

\section{Pengaruh Efikasi Diri Terhadap Komitmen Organisasi}

Berdasarkan hasil pengujian statistik menunjukkan bahwa efikasi diri berpengaruh postif dan signifikan terhadap komitmen organisasi, hal tersebut dapat dilihat dari nilai original sampel 0,678 (positif) dan $p$ value $0,000<0,05$. Hasil penelitian ini menunjukkan bahwa dosen yang memiliki efikasi diri yang kuat akan mampu mengembangkan sikap yang positif terhadap pekerjaan. Efikasi diri yang kuat juga akan membuat individu merasakan kontrol internal yang kuat atas pekerjaan yang dilakukan, individu merasa lebih berkomitmen, lebih terlibat, dan lebih menikmati pekerjaannya, dan dalam melakukan aktivitas pekerjaannya, individu lebih didorong 
oleh minat instrinsiknya. Efikasi diri merupakan salah satu aspek pengetahuan tentang diri atau self knowledge yang paling berpengaruh dalam kehidupan manusia sehari-hari. Hal ini disebabkan efikasi diri yang dimiliki ikut mempengaruhi individu dalam menetukan tindakan yang akan dilakukan untuk mencapai suatu tujuan termasuk di dalamnya berbagai perkiraan kejadian yang akan dihadapi. Abidin et al. (2016) mengemukakan bahwa efikasi diri akan menentukan bagaimana pegawai dapat menyelesaikan tugas tertentu, kemampuannya dalam menghadapi kesulitan atau kegagalannya akan sangat mempengaruhi tingkat komitmen organisasi.

Temuan penelitian ini sejalan dengan penelitian Agarwal \& Mishra (2016) memperlihatkan hasil bahwa efikasi diri berpengaruh signifikan terhadap komitmen organisasional. Zeb \& Nawaz (2016), menunjukkan hasil efikasi diri mempengaruhi secara positif terhadap komitmen organisasional dosen di tingkatan universitas. Juga didukung oleh penelitian Verianto (2019) dimana efikasi diri mempengaruhi secara signifikan terhadap komitmen organisasional karyawan.

\section{Pengaruh Kualitas Kehidupan Kerja Terhadap Komitmen Organisasi}

Berdasarkan hasil pengujian statistik menunjukkan bahwa efikasi diri berpengaruh postif dan signifikan terhadap komitmen organisasi, hal tersebut dapat dilihat dari nilai original sampel 0,678 (positif) dan pvalue $0,000<0,05$. Hasil penelitian ini menunjukkan bahwa apabila universitas mampu memberikan kualitas kehidupan kerja yang baik kepada dosen maka ikatan emosional positif dosen terhadap universitas akan dapat tercipta, sehingga komitmen dosen dalam menjalankan kegiatan Tri Dharma perguruan tinggi akan semakin meningkat, selain itu kualitas kehidupan kerja yang baik akan berdampak pada tidak ada niat dosen untuk meninggalkan universitas, mereka akan merasa bahwa masalah yang terjadi di universitas adalah masalah pribadi dosen juga.

Konsep kualitas kehidupan kerja (Quality Work of Life) pada dasarnya mengungkapkan pentingnya nilai penghargaan terhadap manusia dalam lingkungan kerjanya sehingga konsep tersebut menjadi landasan utama bagi manajemen suatu perusahaan untuk mengelola tenaga karyawan. Selain mengungkapkan pentingnya nilai penghargaan terhadap manusia dalam lingkungan kerja, kualitas kehidupan kerja juga memiliki peran penting untuk mengubah iklim organisasi agar secara teknis dan manusiawi dapat membawa suatu perusahaan kepada kualitas kehidupan kerja yang lebih baik, (Muraga, Tewal, dan Dotulong, 2019).

Temuan penelitian ini sejalan dengan penelitian Kaunang, Pio, \& Roring (2017) dimana dalam penelitianya menunjukkan bahwa kualitas kehidupan kerja berpengaruh positif dan signifikan terhadap komitmen organisasional. Hal tersebut juga didukung oleh penelitian dari Maharani, (2018) yang menyatakan bahwa adanya hubungan yang signifikan antara kualitas kehidupan kerja dengan komitmen organisasi. Penelitian Muraga, Tewal, dan Dotulong (2019) juga menunjukkan bahwa variabel kualitas kehidupan kerja memiliki pengaruh yang signifikan terhadap komitmen organisasi.

\section{Kesimpulan}

Penelitian ini memberikan kesimpulan bahwa efikasi diri mempunyai pengaruh positif dan signifikan terhadap komitmen organisasi, artinya semakin baik tingkat efikasi diri seorang dosen maka akan semakin tinggi komitmen organisasi. Kualitas kehidupan kerja mempunyai pengaruh positif dan signifikan terhadap komitmen organisasi, artinya semakin baik tingkat kualitas kehidupan kerja maka akan semakin tinggi komitmen organisasi.

Berdasarkan hasil penelitian ini, disarankan kepada pihak universitas agar memberikan kompensasi yang layak, meningkatkan fasilitas kerja dan peningkatan pengembangan karir agar komitmen organisasi dosen semakin meningkat. Kontribusi yang diberikan dari variabel efikasi diri dan kualitas kehidupan kerja terhadap komitmen organisasi sebesar $70,6 \%$, sehingga pihak universitas masih perlu memperhatikan faktor-faktor lain yang dapat mempengaruhi komitmen organisasi seperti variabel disiplin kerja, lingkungan kerja, kepuasan kerja, gaya kepemimpinan, motivasi kerja, dan variabel lainnya agar dapat berguna bagi universitas dan memperkaya hasil penelitian. Penelitian ini juga memliki keterbatasan penelitian dimana metode pengumpulan data hanya menggunakan kuesioner, sehingga sangat mungkin datanya bersifat subyektif, akan lebih baik bila ditambahkan metode wawancara sehingga hasil penelitian yang diperoleh lebih lengkap.

\section{Daftar Pustaka}

Abidin, M.I.Z., Pangtuluran, Y., \& Maria, S. (2016), Pengaruh Kepuasan Kerja, Lingkungan Kerja Dan Efikasi Diri Terhdapa Komitmen Organisasi Di Rumah Sakit Smc Samarinda. AKUNTABEL: Jurnal Ekonomi dan keuangan. 13(1).

Adikoeswanto, D., Eliyana, A., Hamidah., Sariwulan, T., Buchdadi, A.D., \& Firda, F. (2020). Quality of Work Life's Factors and Their Impacts on Organizational Commitments, Systematic Reviews in Pharmacy, 11(7). 
Agarwal, S., \& Mishra, P. (2016). Self Efficacy as Predictor of Organizational Commitment among Revenue Personnel. The Internaional Journal of Indian Psychology, 3(4), 44-52.

Akhtar, S., Ghayas, S., \& Adil, A. (2013). Self-efficacy and optimism as predictors of organizational commitment among bank employees. International Journal of Research Studies in Psychology, 2(2), 33-42.

Asharini, N. A., Hardyastuti, S., \& Irham, I. (2018). The Impact of Quality of Work Life and Job Satisfaction on Employee Performance of PT. Madubaru PG-PS Madukismo. Agro Ekonomi, 29(1), 146. https://doi.org/10.22146/ae.31491.

Chrisienty, W. (2015). Pengaruh Quality of Work Life Terhadap Komitmen Organisasional Karyawan di CV Sinar Plasindo. Agora, 3(2), 483-490.

Endayani, F., \& Saman, (2020). Dampak Kualitas Kehidupan Kerja Dan Motivasi Kerja Pada Employee Engagement. Jurnal Bisnis dan Manajemen. 8(1). Hal 1-6.

Fitriani, Desy \& Purwanto, Edi (2019). Pengaruh Pusat Kendali Internal dan Eksternal, Efikasi Diri dan Kepuasan Kerja terhadap Komitmen Organisasional Karyawan pada PT. Pasifik Teknologi Indonesia. Business Management Journal. 15 (1) 1-67.

Ghozali, I., \& Latan, H. (2016), Partial Least Square: Konsep, Metode, dan Aplikasi menggunakan program WarpPLS 5.0, Edisi ke-3, Semarang: Badan Penerbit Universitas Diponogoro.

Giri, E. E., Nimran, U., Hamid, D., \& Musadieq, M. Al. (2016). The Effect of Organizational Culture and Organizational Commitment to Job Involvement Knowledge Sharing, and Employee Performance: A Study on Regional Telecommunications Employees of PT Telkom East Nusa Tenggara Province, Indonesia. Indonesia. International Journal of Management and Administrative Sciences (IJMAS), 3(4), 20-33.

Garcia, G. F. (2015). The Relationship between self-efficacy and employee commitment among perfusionists. Walden University.

Hair, J. F., Hult, G. T. M., Ringle, C., \& Sarstedt, M. (2017). A Primer on Partial Least Squares Structural Equation Modeling (PLS-SEM) 2nd Edition. Sage Publications.

Hashempour, R., Hosseinpour Ghahremanlou, H., Etemadi, S., \& Poursadeghiyan, M. (2018). The Relationship Between Quality of Work Life and Organizational Commitment of Iranian Emergency Nurses. Health in Emergencies \& Disasters Quarterly, 4(1), 49-54. https://doi.org/10.32598/hdq.4.1.49.

Helastika, D. O., \& Izzati. A. (2019), Hubungan Antara Kualitas Kehidupan Kerja dengan Komitmen Organisasi pada Karyawan bidang Operasi PT. "X". Jurnal Penelitian Psikologi. 6(3).

Indaswari, F.A. (2014). Analisis Pengaruh Kualitas Kehidupan Kerja Dan Komitmen Organisasi Terhadap Kinerja Karyawan. Jurnal UNDIP Semarang. 14 (05) hal 1-7.

Jehanzeb, K., \& Mohanty, J. (2018). Impact of employee development on job satisfaction and organizational commitment: person-organization fit as moderator. International Journal of Training and Development, 22(3), 171-191. https://doi.org/10.1111/ijtd.12127.

Kaswan. (2017). Psikologi Industri dan Organisasi. Bandung: Alfabeta.

Kaunang, F. F., Pio, R. J., \& Roring, M. (2017). Pengaruh Kualitas Kehidupan Kerja Terhadap Komitmen Organisasional pada PT. Hasjrat Abadi Manado. Jurnal Administrasi Bisnis Unsrat, (c), 2-6.

Larasati, D.P., \& Hasanati, N. (2018), The Effects of Work-Life Balance towards Employee Engagement in Millennial Generation, Proceedings of the 4th ASEAN Conference on Psychology, Counselling, and Humanities (ACPCH 2018), https://doi.org/10.2991/acpch-18.2019.93

Maharani, R. D. (2018). Pengaruh Kualitas Kehidupan Kerja dan Lingkungan Kerja terhadap Komitmen Organisasi Karyawan (Studi Pada Divisi Peralatan Industri Agro PT. Barata Indonesia (Persero) Gresik). Jurnal Bisnis Dan Manajemen (BISMA),1(2). 
Manurung, S. (2016), Meningkatkan Efektivitas Kerja Dosen Melalui Penjaminan Mutu Dan Efikasi Diri, Jurnal IImu dan Teknologi Kesehatan, 3(2), hal : 137-146.

Maria, S., Lestari, D., Rochaida, E., Darma, D.C., \& Rahmawati, H.R. (2021). Self-Efficacy, Organizational Commitment, And Employee Performance - From Public Office. Cactus Tourism Journal. 1(3). 6-15.

Muraga, A.Z., Tewal, B., \& Dotulong, L.O.H, (2019), Pengaruh Kualitas Kehidupan Kerja, Motivasi Dan Kepemimpinan Terhadap Komitmen Organisasi Pada Bank Sulutgo Cabang Utama Manado, Jurnal EMBA, 7(4), 5914-5923.

Noviana, U., \& Rijanti, T, (2014), Pengaruh Kualitas Kehidupan Kerja Dan Komunikasi Dengan Kepuasan Kerja Dan Komitmen Organisasional Sebagai Variabel Intervening Terhadap Kinerja Pegawai (Studi Pada Lpmp Provinsi Jawa Tengah), Telaah Manajemen, 2(1), Hal 103 - 116.

Risdwiyanto, A., \& Kurniyati, Y. (2015). Strategi Pemasaran Perguruan Tinggi Swasta Di Kabupaten Sleman Yogyakarta Berbasis Rangsangan Pemasaran, Maksipreneur. 5(1), pp. 1-23.

Sajjad, N. K., \& Abbasi, B. (2014). Studying The Relationship Between Quality of Work Life and Organizational. Research Journal of Recent Sciences, 3(2).

Sinaga, O, (2018), Pengaruh Efikasi Diri Dan Kemampuan Manajemen, Terhadap Komitmen Normatif Dosen Di Universitas Quality Medan, Jurnal Manajemen Pendidikan, 11(2), 42-51.

Sudiq, R.A.S.D., \& Wijayanti, D.T. (2020), Pengaruh Kualitas Kehidupan Kerja Terhadap Komitmen Organisasi Melalui Kepuasan Kerja Pada Pt. Segar Murni Utama. Jurnal IImu Manajemen. 8(3). Hal 921-930.

Sugiyono. (2017). Metode Penelitian Kuantitatif, Kualitatif, dan R\&D. Bandung: Alfabeta.

Sumual, M.G.V, (2014), Effect Of Empowerment, Self Efficacy, And Lecturer To Proffession's Commitment Of The Manado State University, International Journal of Business and Management Invention, 3(5), 18-27.

Totoh, A. (2020). Daya Saing Perguruan Tinggi Swasta. https://kumparan.com/asep-totoh/daya-saing-perguruantinggi-swasta-1tIFeZiUYzx/full. Diakses pada tanggal 05 September 2021.

Valentine, S. (2014). Organizational Ethics and Stakeholder Well Being in The Business Environment. USA: Information Age Publishing.

Verianto, H. (2019), 1Pengaruh Kepercayaan, Efikasi Diri, dan Komitmen Organisasional Terhadap Berbagi Pengetahuan Karyawan di Kantor Cabang Utama PT Bank Panin Tbk Kota Pontianak, Jurnal Ekonomi Bisnis dan Kewirausahaan (JEBIK), 8(2), Hal 128-146.

Widodo, S., Widiyanti, M., Hidayati, T., \& Situmorang, N. (2019). Human resources management facets: role of organizational commitment, Journal of Security and Sustainability, 9(1), 617-630.

Yokoyama S. (2019). Academic self-efficacy and academic performance in online learning: a mini review. Frontiers in Psychology, 9(2794), 1-4.

Zeb, S., \& Nawaz, A. (2016). Impacts of Self-Efficacy on Organizational Commitment of Academicians A Case of Gomal University, Dera Ismail Khan, Khyber Pakhtunkhwa, Pakistan. Information and Knowledge Management, 6(1), 36-42. 